\title{
Analysis and optimization of water-based printing ink formulations for polyethylene films
}

\author{
Jar Carlo C. Ramirez and Terence P. Tumolva* (D)
}

\section{*Correspondence:}

tptumolva@up.edu.ph

Department of Chemical

Engineering, University of the

Philippines Diliman, Quezon

City, Philippines

\begin{abstract}
Water-based ink formulations containing wax, surfactant, and defoamer additives were prepared and printed on polyethylene film substrates. Standard test methods for adhesion, rub resistance, and gloss were done on the printed polyethylene films. Quantitative methods for the assessment and evaluation of the three print properties were developed. Image analyses were done to quantify adhesion and rub resistance. Quantitative measurement was done to quantify gloss. Data were analyzed using mixture design modelling and optimization. Modelling results show that adhesion and gloss are described by special cubic model equations, while rub resistance is described by a linear model equation. Contour plots and 3D surface graphs were generated showing the response surfaces of the print properties. The effects of varying the mass fractions of wax, surfactant, and defoamer on adhesion, rub resistance, and gloss were determined. It was found that increasing wax increases rub resistance, while increasing surfactant increases gloss, and increasing defoamer increases adhesion. There is dependency found between the mass fraction of wax, surfactant and defoamer with respect to the rub resistance, adhesion and gloss. Multi-objective optimization revealed that optimum adhesion, rub resistance, and gloss is obtained by a formulation containing equal mass fractions of wax and surfactant but no defoamer.
\end{abstract}

\section{Background}

The ink industry is one of the growing markets in the world, particularly due to increasing market of printing inks for packaging applications [1]. Currently, there are two types of printing inks based on composition: (1) solvent-based inks that are formulated using solvents an (2) water-based inks that are formulated using water as solvent. The volatile organic compounds present in solvent-based inks result in environmental issues regarding their use, which lead to the increasing demand for the more environment-friendly water-based inks [2].

Water-based printing inks have been successfully used in different printing applications, all of them involving application of the ink on various surfaces or substrates [1]. While solvent-based inks have been successfully used on both porous substrates (e.g., paper) and non-porous substrates (e.g., plastic), water-based inks are found to be incompatible to non-porous substrates, resulting to poor substrate wetting. This poor ink-substrate adhesion due to the water's inherently high surface tension: non-porous substrates

(c) The Author(s) 2018. This article is distributed under the terms of the Creative Commons Attribution 4.0 International License (http://creativecommons.org/licenses/by/4.0/), which permits unrestricted use, distribution, and reproduction in any medium, provided you give appropriate credit to the original author(s) and the source, provide a link to the Creative Commons license, and indicate if changes were made. 
like polyethylene films have a surface energy of $28-32 \mathrm{mN} / \mathrm{m}$, while water has a surface energy of $73 \mathrm{mN} / \mathrm{m}$. Substrate wetting has been a main problem in the use of waterbased inks for printing in non-porous substrates, and to achieve successful substrate wetting, the surface tension of the ink must be lower than the surface energy of the substrate to be printed on [3].

Currently, there are two ways to solve the adhesion problem of water-based inks on non-porous substrates: surface treatment (substrate modification) or changes in the ink formulation (ink modification). Surface treatments such as corona discharge treatment and plasma treatment [4] are done to increase the surface energy of the substrate by introducing functional groups in the surface that would improve the adhesion of ink on the surface [5]; however, the effect of the surface treatment is reversible with the dissipation of the induced increase in surface energy. Corona treatment can also lead to unwanted physical changes in the surface if it is overtreated, and can be very costly. Thus, modification of ink formulation is considered as the alternative approach done in the ink industry.

Studies on the effects of the different ink components on the ink and print properties have been previously investigated, such as the addition of emulsion polymers for delivering ink properties after ink formulated [6]; among these studies, ink additives are deemed of particular importance. Additives are defined as "any substances that are added in small quantities to a coating material to improve or modify certain properties of the finished coating or of the coating material during its manufacture, storage, transport, or application" [3]. They are generally added to ink formulations at maximum of 5\% by weight, where typical amounts are about $1.5 \%$ of the total weight of the ink. However, because additives have significant effect on inks in just small additions in the formulations, they are considered by researchers as points for improvement.

Several studies for ink additives and performance additives that would improve the print properties of water-based ink formulations [2]. Three additives generally used: (1) surfactants, (2) defoamers and (3) waxes. Surfactants are added to reduce the surface tension of water-based inks to allow adhesion on nonporous substrates; however, the presence of surfactants in the formulation results to production of stable foam during mixing. To address this problem, defoamers or anti-foaming agents are also added used as additives together with the surfactants in the formulations of printing inks. On the other hand, waxes are used to impart essential surface properties such as abrasion resistance.

To determine the effects of these additives, the most important print properties of the ink with modified formulation are analyzed- namely, adhesion, rub resistance, and gloss. Adhesion and rub resistance are two important mechanical properties, while gloss is an optical property that is deemed important in many applications, such as in packaging. To evaluate ink performance and analyze ink formulations, modern techniques and classical chemical tests are done by manufacturers to establish quality and applicability of their products [7], as well as standard test methods that involve qualitative assessment. While there is a quantitative standard test method for gloss such as the ASTM Standard Test Method for Specular Gloss D523-14, adhesion and rub resistance test methods are mostly qualitative, such as the color fastness analysis on a grey scale for testing rub resistance [8] and ASTM F2252-03 peel test [9]. Hence, quantitative methods 
for evaluating adhesion and rub resistance must be developed to obtain more accurate and reliable results and to allow for performing optimization with the quantitative gloss measurements. In this study, an image-based technique is developed and employed to quantify adhesion and rub resistance, and to analyze the effects of varying the relative amounts of the three additives on the three identified print properties. After gathering and analyzing the results, a formulation that would give best print properties is identified by using optimization methods.

\section{Methods}

\section{Ink preparation}

Table 1 shows the identity of the different components of the ink formulations. In this study, the design of experiment used is a mixture design, where three components of an original water-based ink formulation are used as variables [10]. Prior to the mixture design, the original formulation was initially modified by adjusting the fraction of the emulsion polymer, the wax and defoamer (shown in Table 2) and a non-ionic, siliconfree surfactant was added as a new component. The relative amounts of the surfactant, wax, and defoamer were then varied to make different ink formulations. A total of ten (10) formulations were done, including a control sample with no surfactant.

The preparation of the ink formulations included two parts: the millbase and the letdown. In the millbase, the pigment, solution polymer, water, defoamer, and surfactant were first added together and mixed in a glass bottle. Afterwards, glass beads were added to grind the pigment to the required particle size of $5 \mu$. The amount of glass beads is

Table 1 List of ink components

\begin{tabular}{ll}
\hline Component & Description \\
\hline Pigment & Carbon black \\
Solution polymer & Styrene-acrylic polymer \\
Emulsion polymer & Styrene-acrylic polymer \\
Surfactant & Alkoxylated alcohol \\
Defoamer & Mineral oil \\
Wax & Micronized polyethylene \\
Water & Industrial/tap water \\
\hline
\end{tabular}

Table 2 Water-based ink formulation

\begin{tabular}{|c|c|c|c|c|c|}
\hline \multicolumn{2}{|l|}{ Original } & \multicolumn{2}{|l|}{ Modified } & \multicolumn{2}{|l|}{ Mixture design } \\
\hline Component & Quantity & Component & Quantity & Component & Quantity \\
\hline Pigment & 7.00 & Pigment & 7.0 & Pigment & 7.0 \\
\hline Water & 2.50 & Water & 2.4 & Water & 2.4 \\
\hline Solution polymer & 8.75 & Solution polymer & 8.8 & Solution polymer & 8.8 \\
\hline Emulsion polymer & 67.75 & Emulsion polymer & 67.6 & Emulsion polymer & 67.2 \\
\hline Water & 11.38 & Water & 11.4 & Water & 11.4 \\
\hline Wax 1 & 1.82 & Wax 1 & 2.4 & Wax & 3.2 \\
\hline Wax 2 & 0.50 & Surfactant & 0 & Surfactant & \\
\hline Defoamer & 0.30 & Defoamer & 0.4 & Defoamer & \\
\hline Total & 100.00 & Total & 100.0 & Total & 100.0 \\
\hline
\end{tabular}


equal to the total amount of the ink components in the millbase. The container was then closed and placed in a shaker for $1 \mathrm{~h}$. The millbase viscosity was controlled for proper pigment grinding and also to prevent breaking the container.

In the letdown, the remaining ink components are added into the millbase. A small amount of the ink millbase is placed on the grind measurement table and the grind is determined by drawing it down and measuring the distance that the ink reaches; the acceptable grind is equivalent to that of the distance attained in the particle size is within 4-5 $\mu \mathrm{m}$. After passing the grind checking, the letdown components are then added. The emulsion polymers are added, followed by wax, and finally the remaining water for the formulation. Once the components are added, the container is closed and it is mixed in the shaker for $10 \mathrm{~min}$. After shaking the letdown for $10 \mathrm{~min}$, the beads are removed from the ink, and the ink is placed in a new container, as shown in Fig. 1.

\section{Printed samples preparation}

Formulated water-based inks were printed on untreated polyethylene film substrates by drawdown method. Drawdown was done carefully to achieve successful substrate wetting and to ensure that microfoams were not present on the ink that could cause print defects. After printing, the printed polyethylene film was dried initially using a blower for $10 \mathrm{~s}$, and then was allowed to dry for $24 \mathrm{~h}$ to cure the ink (a sample of a printed film is shown in Fig. 2 below).

Three sets of printed polyethylene films were made for each set of ink samples, 1 set for each print property. Eighty printed polyethylene films were made in total.

\section{Print property tests}

Three tests were done, one for each print property (adhesion, rub resistance, and gloss). The tests done were standard test methods used by the local industry for evaluating print properties of water-based inks. For adhesion, the adhesion tape test method was done, using a standard $3 \mathrm{M}$ tape, 1-1.5 in. long, and manually pulling off the tape to determine the degree of ink adhesion or ink removal from the substrate. The results were interpreted as either percent ink adhesion or percent ink removal. For the rub resistance test, a rub tester machine was used. A 2-lb weight was placed on top of the substrate and then rubbed back and forth for a set of 20 cycles, which corresponds to 40 rubs in total. The resulting degree of rubbing was recorded, as it is considered as inversely related to the rub resistance. For the gloss measurement method, a glossmeter set at $60^{\circ}$ angle of light reflection was used to measure the gloss of the ink substrate in terms of gloss units.

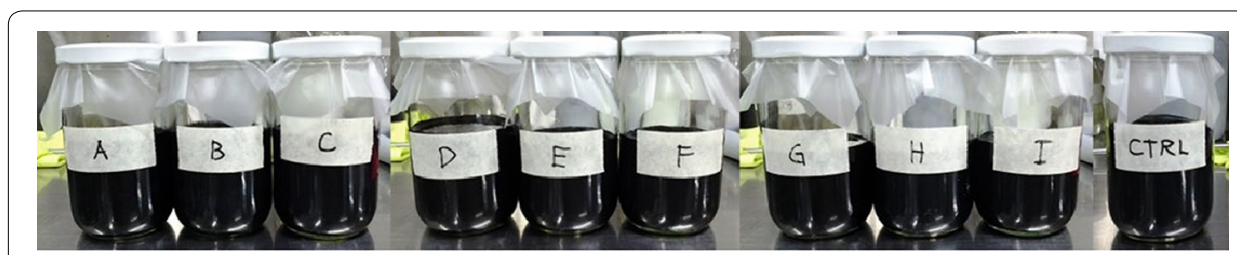

Fig. 1 Prepared ink formulation samples based on the mixture design for the three additives (wax, surfactant, defoamer) 


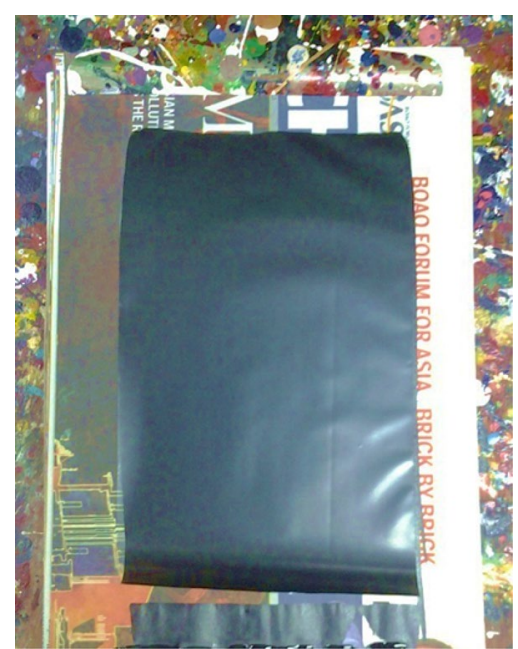

Fig. 2 Printed ink film sample

\section{Data analysis}

Image analysis was chosen as a method to have a more accurate and meaningful quantitative method for the responses adhesion and rub resistance tests, which are currently only evaluated qualitatively. Printed polyethylene films substrates from the three print property tests were scanned to obtain digital images. For adhesion test samples, the images were derived from the printed film parts where the tapes had been peeled off. For rub resistance test samples, the printed film parts that were rubbed by the rub tester were selected and cropped. Same image sizes were cropped per response to make results comparable.

Quantitative image analysis was done for determining the adhesion and rub resistance of all printed polyethylene film samples using Image ${ }^{\circledR}$ image processing software. Each scanned image was analyzed for its pixel histogram, where the different grey-scale values (ranging from 0 to 255) and their corresponding pixel counts. For adhesion, the percent adhered ink can be quantified in terms of the number of pixels in the scanned image (see Fig. 3). After determining the number of pixels of adhered ink, its percentage with respect to the total number of pixels can be determined.

For the rub resistance, quantification was expressed in terms of the degree of change in color of the rubbed areas of the printed ink. Unlike in adhesion test analysis, the partial rubbing resulted in a range of shades of black and dark gray (as shown in Fig. 4) and is thus more difficult to analyze; however, by using Image ${ }^{\circledR}$, the color change in greyscale value (within a range of 0-255) per pixel were determined: the image is converted into 8-bit and the background is adjusted until the image is completely made up of black (grey-scale value of 0 ) and white (grey-scale value of 255) pixels. The grey-scale color value change per pixel can then be determined by dividing the total grey-scale color value change with the total number of pixels in the scanned image (the pixel counting is done using ImageJ). Because the rubbed ink can be represented both by the white and black pixels, the absolute grey-scale value of the color change of a pixel is used, and the rub resistance is measured based on the total number of pixels with lower absolute 


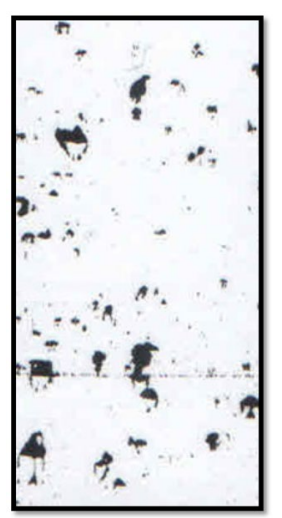

Scanned Image

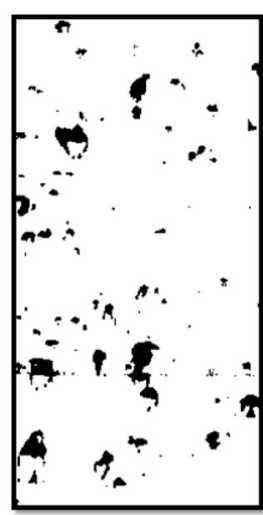

Processed Image

Fig. 3 Sample results from adhesion test using Image $^{\circledR}$
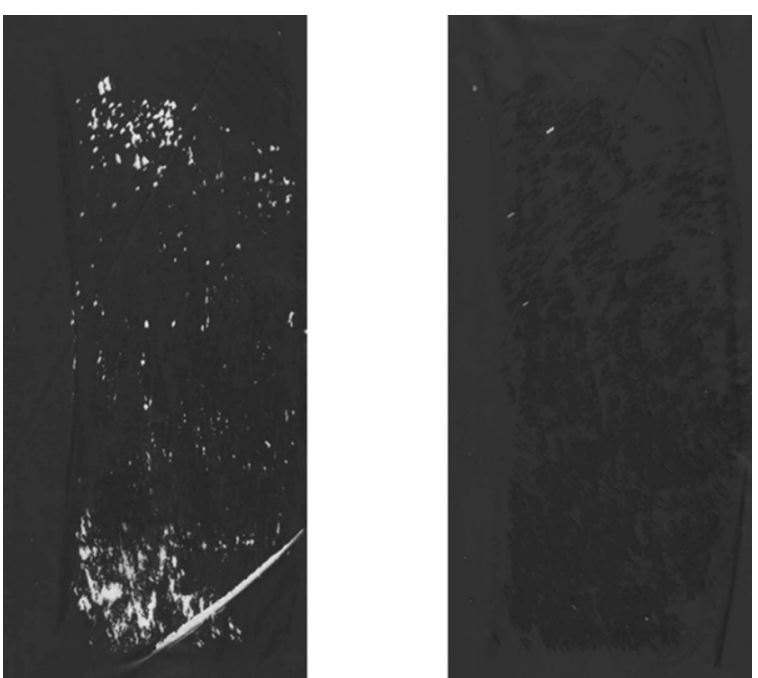

Fig. 4 Processed image from rub resistance test using Image $J^{\circledR}$ (left) and the scan of the original rub resistance test sample

values relative to the number of dark background (i.e., number of black pixels multiplied by its grey-scale value of 255 ).

The quantified pixel values obtained were considered as indirectly proportional to the rub resistance of an ink film: the higher the color value change of a rubbed ink film, the higher the extent of rubbing and, equivalently, the lower the rub resistance. The inverse of the color value change per pixel was therefore used as the quantitative measure of rub resistance.

\section{Modeling and optimization}

Modeling of the three print properties with respect to the three ink components was done using response surface methodology [11], using the quantified data of the experimental responses to develop multivariate equations that were solved simultaneously [12]. Mixture design response surface methodology was used since the mixture system 
being studied has three or more components and one or more responses are analyzed and considered. Modeling and optimization methods were performed using Design Expert $^{\circledR}$.

The summary of the mixture design of the three additives and the ten ink formulations are shown in Tables 3, 4.

Modeling was done by performing regression calculations to fit three different polynomial models to the data (linear, quadratic, special cubic) and polynomial fitting statistical analyses were performed for the comparison. Each response was analyzed one at a time, and each analysis includes model fit summary, analysis of variance (ANOVA), and model graphs generation using whichever model came up with the best degree of fit.

Finally, model graphs of each response were generated to interpret and evaluate the model equations used. The contour plots of the mixture design model were two-dimensional representations of the responses plotted against combinations of the mixture components. The response is shown as contour lines in the graph, indicating the actual values of the responses corresponding to the mass fractions of the components. The three-dimensional surfaces of the response models were also generated to provide better visual representation of the response surfaces in the design space.

\section{Results and discussion}

\section{Adhesion and rub resistance analysis}

A summary of the quantified results for the adhesion test is presented in the Table 5 . Based on the results, it can be observed that the percent adhesion values of the 10 ink

Table 3 Mixture design of the three additives (mass fractions)

\begin{tabular}{lllll}
\hline Point & Wax & Surfactant & Defoamer & Total \\
\hline A & 0.50 & 0.25 & 0.25 & 1.00 \\
B & 0.25 & 0.50 & 0.25 & 1.00 \\
C & 0.25 & 0.25 & 0.50 & 1.00 \\
D & 0.50 & 0.50 & - & 1.00 \\
E & - & 0.50 & 0.50 & 1.00 \\
F & 0.50 & - & 0.50 & 1.00 \\
G & - & 1.00 & - & 1.00 \\
H & - & - & 1.00 & 1.00 \\
I & 1.00 & - & - & 1.00 \\
\hline
\end{tabular}

Table 4 Summary of ink formulations

\begin{tabular}{lcccccccccc}
\hline Component & A & B & C & D & E & F & G & H & I & CTRL \\
\hline Pigment & 7.0 & 7.0 & 7.0 & 7.0 & 7.0 & 7.0 & 7.0 & 7.0 & 7.0 & 7.0 \\
Water & 2.4 & 2.4 & 2.4 & 2.4 & 2.4 & 2.4 & 2.4 & 2.4 & 2.4 & 2.4 \\
Solution polymer & 8.8 & 8.8 & 8.8 & 8.8 & 8.8 & 8.8 & 8.8 & 8.8 & 8.8 & 8.8 \\
Emulsion polymer & 67.2 & 67.2 & 67.2 & 67.2 & 67.2 & 67.2 & 67.2 & 67.2 & 67.2 & 67.2 \\
Water & 11.4 & 11.4 & 11.4 & 11.4 & 11.4 & 11.4 & 11.4 & 11.4 & 11.4 & 11.4 \\
Wax & 1.6 & 0.8 & 0.8 & 1.6 & 0 & 1.6 & 0 & 0 & 3.2 & 2.4 \\
Surfactant & 0.8 & 1.6 & 0.8 & 1.6 & 1.6 & 0 & 3.2 & 0 & 0 & 0 \\
Defoamer & 0.8 & 0.8 & 1.6 & 0 & 1.6 & 1.6 & 0 & 3.2 & 0 & 0.4 \\
\hline
\end{tabular}


Table 5 Adhesion image analysis results

\begin{tabular}{lllll}
\hline Formulation & Wax & Surfactant & Defoamer & \% Adhesion \\
\hline CTRL & 0.86 & 0 & 0.14 & 5.70 \\
A & 0.5 & 0.25 & 0.25 & 4.60 \\
B & 0.25 & 0.5 & 0.25 & 4.81 \\
C & 0.25 & 0.25 & 0.5 & 4.43 \\
D & 0.5 & 0.5 & - & 5.52 \\
E & - & 0.5 & 0.5 & 4.54 \\
F & 0.5 & - & 0.5 & 5.45 \\
G & - & 1 & - & 4.04 \\
H & - & - & 1 & 6.02 \\
I & 1 & - & - & 5.34 \\
\hline
\end{tabular}

formulations are close relative to each other. The ink with the highest \% adhesion is Formulation $\mathrm{H}$ which contains only the defoamer, which indicates that the defoamer most significant effect in improving ink-substrate adhesion.

The summary of the quantified results for the rub resistance test is presented in Table 6, showing the color change per pixel values of the different ink formulations as a measure of the rub resistance. Based from the results, the ink with the best rub resistance (lowest color change per pixel) is the CTRL formulation (contains large fraction of wax and small fraction of defoamer), which indicates that wax has the most significant effect in improving rub resistance.

\section{Gloss analysis}

A summary of the results for gloss is presented in the Table 7, showing the gloss unit values of the ink formulations. It can be seen from the results that Formulation $G$ has the highest gloss value-about double of those of the majority-which indicates that the surfactant has most significant effect in improving the gloss of the printed ink.

\section{Mixture design}

A summary of all the mixture design inputs used in the software is presented in Table 8 below. The mixture design type includes selected inner points corresponding to the three-component formulations (formulations containing wax, surfactant, and defoamer)

Table 6 Rub resistance image analysis results

\begin{tabular}{lllll}
\hline Formulation & Wax & Surfactant & Defoamer & Rub resistance \\
\hline CTRL & 0.86 & 0 & 0.14 & 0.340 \\
A & 0.5 & 0.25 & 0.25 & 0.207 \\
B & 0.25 & 0.5 & 0.25 & 0.143 \\
C & 0.25 & 0.25 & 0.5 & 0.171 \\
D & 0.5 & 0.5 & - & 0.262 \\
E & - & 0.5 & 0.5 & 0.142 \\
F & 0.5 & - & 0.5 & 0.225 \\
G & - & 1 & - & 0.200 \\
H & - & - & 1 & 0.165 \\
I & 1 & - & - & 0.256 \\
\hline
\end{tabular}


Table 7 Gloss data analysis results

\begin{tabular}{lllll}
\hline Formulation & Wax & Surfactant & Defoamer & Gloss unit \\
\hline CTRL & 0.86 & 0 & 0.14 & 21.4 \\
A & 0.5 & 0.25 & 0.25 & 18.9 \\
B & 0.25 & 0.5 & 0.25 & 19.6 \\
C & 0.25 & 0.25 & 0.5 & 17.1 \\
D & 0.5 & 0.5 & - & 25.5 \\
E & - & 0.5 & 0.5 & 19.2 \\
F & 0.5 & - & 0.5 & 19.7 \\
G & - & 1 & - & 39.0 \\
H & - & - & 1 & 19.5 \\
I & 1 & - & - & 19.5 \\
\hline
\end{tabular}

Table 8 Mixture design data summary

\begin{tabular}{llllll}
\hline \multicolumn{2}{l}{ Weight fraction } & & \% Adhesion & Rub resistance & Gloss unit \\
\cline { 1 - 3 } Wax & Surfactant & Defoamer & & & \\
\hline 0.5 & 0.25 & 0.25 & 4.60 & 0.207 & 18.9 \\
0.25 & 0.5 & 0.25 & 4.81 & 0.143 & 19.6 \\
0.25 & 0.25 & 0.5 & 4.43 & 0.171 & 17.1 \\
0.5 & 0.5 & 0 & 5.52 & 0.262 & 25.5 \\
0 & 0.5 & 0.5 & 4.54 & 0.142 & 19.2 \\
0.5 & 0 & 0.5 & 5.45 & 0.225 & 19.7 \\
0 & 1 & 0 & 4.04 & 0.200 & 39.0 \\
0 & 0 & 1 & 6.02 & 0.165 & 19.5 \\
1 & 0 & 0 & 5.34 & 0.256 & 19.5 \\
\hline
\end{tabular}

and a cubic model equation to get a more accurate model of the responses. The mixture design imposes special constraints in the response surface methodology since the fractions are bound with a constraint for their total [13].

The results for the responses are presented in Table 9. Polynomial model fitting was done for each response, and the best fit model was determined and suggested by the software. From the results, it can be observed that adhesion and gloss can be best represented by a special cubic model equation, which is the model selected for the study. On the other hand, rub resistance can be best represented by a linear model equation.

Table 9 Design summary

\begin{tabular}{llll}
\hline Response & \% Adhesion & Rub resistance & Gloss \\
\hline Observation & 9 & 9 & 9 \\
Analysis & Polynomial & Polynomial & Polynomial \\
Model & Special cubic & Linear & Special cubic \\
Min & 4.04 & 0.142 & 17.1 \\
Max & 6.02 & 0.262 & 39.0 \\
Mean & 4.97 & 0.197 & 22.0 \\
Std dev & 0.640 & 0.0451 & 6.79 \\
\hline
\end{tabular}




\section{Adhesion}

The results of model fitting and analysis of variance (ANOVA) for adhesion test are presented in Tables 10, 11. For mixture design, the main terms that represent the three factors (three ink components) in the model are already deemed significant; hence, the ANOVA is done only to test the significance of the interaction parameters. In this study, significance is defined by the nearness of the $p$ values of a parameter to that of the model; thus, from the obtained values it can be concluded that the parameters AC, $\mathrm{BC}$ and $\mathrm{ABC}$ have far less significant effects to ink-substrate adhesion. However, before these insignificant terms are removed from the model, fitting error and precision must also be taken into consideration.

The adequate precision is calculated to measure the signal-to-noise ratio. For an adequate signal, a ratio of 4 or greater is desirable. From the results of the adhesion test, the measured adequate precision is 6.38 , which means the set special cubic model can be used to navigate the design space and predict response values. Also, the model has an $R$-squared value of 0.930 , indicating a good data fit even without excluding the insignificant terms.

The cubic model for adhesion with the coefficients from data fitting is given in Eq. 1 . The mixture design equation can then be used to predict the resulting ink-polyethylene substrate adhesion for any given formulation within the range. Among the main factors, the fraction of defoamer has the largest effect on adhesion, followed by that of wax and surfactant; this means that to optimize adhesion, the mass fraction of defoamer relative to wax and surfactant can be increased in the ink formulation. Also, it can be seen that the wax-surfactant interaction has a synergistic effect on adhesion, while the waxdefoamer, surfactant-defoamer and wax-surfactant-defoamer interactions have antagonistic effects

Table 10 ANOVA for adhesion mixture model

\begin{tabular}{llllll}
\hline Source & Sum of squares & Degrees of freedom & Mean square & F value & $\begin{array}{c}\boldsymbol{p} \text { value } \\
\text { Prob }>\boldsymbol{F}\end{array}$ \\
\hline Model & 3.05 & 6 & 0.51 & 4.41 & 0.196 \\
Linear mixture & 1.62 & 2 & 0.81 & 7.02 & 0.125 \\
AB & 0.50 & 1 & 0.50 & 4.37 & 0.172 \\
AC & 0.060 & 1 & 0.060 & 0.52 & 0.545 \\
BC & 0.14 & 1 & 0.14 & 1.21 & 0.386 \\
ABC & 0.37 & 1 & 0.37 & 3.18 & 0.216 \\
\hline
\end{tabular}

Model terms: $\mathrm{A}=$ wax $\mathrm{B}=$ surfactant $\mathrm{C}=$ defoamer

Table 11 ANOVA statistics for adhesion

\begin{tabular}{ll}
\hline Standard deviation & 0.340 \\
Mean & 4.97 \\
Coefficient of variance \% & 6.83 \\
$R$-squared & 0.930 \\
Adequate precision & 6.38 \\
\hline
\end{tabular}




$$
\begin{aligned}
y= & 5.320 x_{A}+4.086 x_{B}+5.996 x_{C} \\
& +3.451 x_{A} x_{B}-1.193 x_{A} x_{C} \\
& -1.814 x_{B} x_{C}-18.13 x_{A} x_{B} x_{C}
\end{aligned}
$$

where $A=$ wax, $B=$ surfactant, $C=$ defoamer.

The contour plot of the model equation determined for the response is shown in Fig. 5, with the color scheme showing the trend of the response is also indicated. The $3 \mathrm{D}$ views of the response surface are shown in Figs. 6, 7. From this study, it is observed that the lowest adhesion value corresponds to Formulation $G$ which contains pure surfactant; thus, increasing the mass fraction of surfactant in the formulation decreases the adhesion. This is because surfactants in general increase adhesion by improving the wetting of the ink on the substrate by the reducing its surface tension [14]. However, too much surfactant present is observed to adversely affect adhesion; therefore, the critical micelle concentration above which all additional surfactant molecules added to the system binds to the micelles [15] must be determined. These excess surfactant micelles are dispersed within the ink system but do not form a layer in the liquid-air interface on the ink surface; instead, excess surfactant can migrate to the ink-substrate interface since it is inherently surface-active and hinder the ink-substrate interaction and cause a decrease in adhesion [16].

On the other hand, it can be seen that highest adhesion would be given by the formulation containing purely defoamer (Formulation $\mathrm{H}$ ). The defoamer causes foam destabilization and breaking via bridging-dewetting mechanism, where a solid particle comes in contact with and bridges opposite surfaces of the foam film. If the particle is sufficiently hydrophobic, it is dewetted by the liquid and perforates the foam film, leading to foam rupture [17] and improved adhesion of the ink film surface during printing.

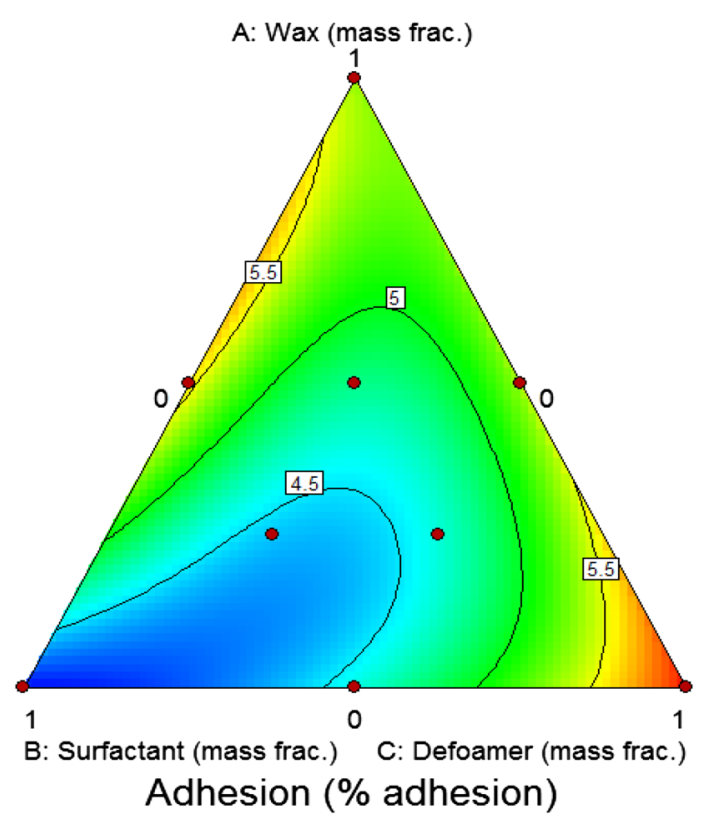

Fig. 5 Adhesion contour plot 


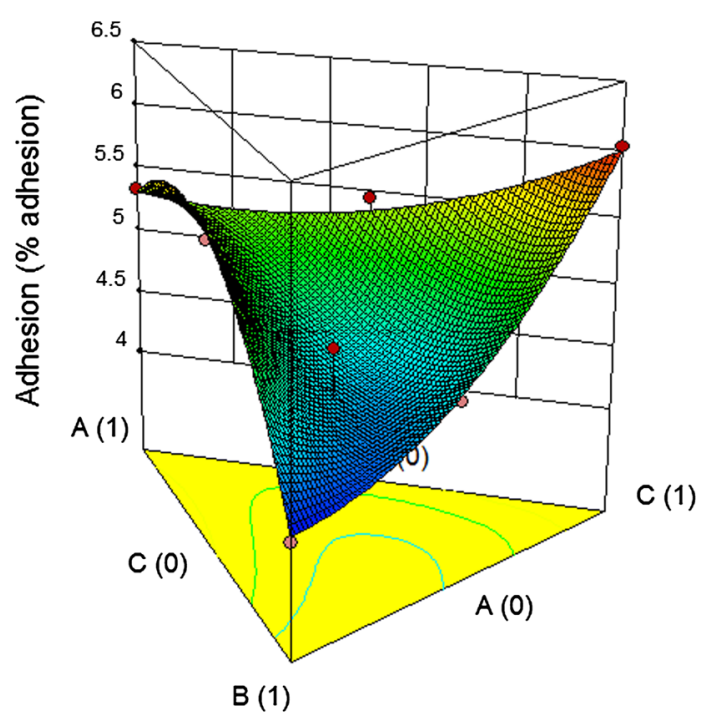

Fig. 6 Adhesion 3D response surface

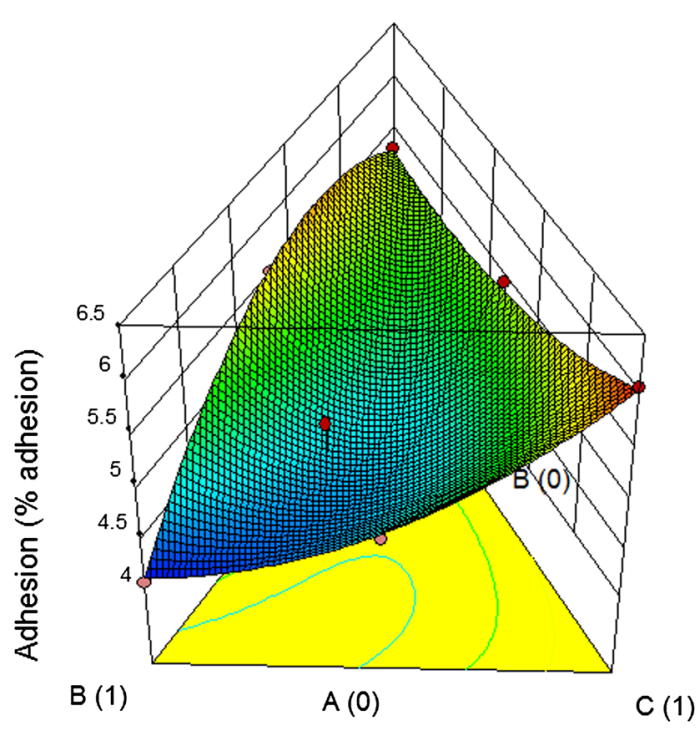

Fig. 7 Adhesion 3D response surface (rotated)

\section{Rub resistance}

The results from model fitting and analysis of variance for rub resistance are presented in Tables 12, 13. Unlike adhesion, model fitting and ANOVA suggest that the best model for the response is linear. The model $F$ value of 5.21 implies that the model is significant, and the $p$ value of 0.0488 that is less than 0.0500 indicates that all terms are significant. The adequate precision measured is 6.703 , indicating that the model can be used to navigate the design space and predict response values. The model also has an $R$-squared value of 0.6346 , which is attributed primarily to the linear model used for the mixture design represented by a first-order equation. 
Table 12 ANOVA for rub resistance mixture model

\begin{tabular}{llllll}
\hline Source & Sum of squares & $\begin{array}{l}\text { Degrees of free- } \\
\text { dom }\end{array}$ & Mean square & F value & $\begin{array}{l}\boldsymbol{p} \text { value } \\
\text { Prob }>\boldsymbol{F}\end{array}$ \\
\hline Model & 0.010 & 2 & 0.00517 & 5.21 & 0.0488 \\
Linear mixture & 0.010 & 2 & 0.00517 & 5.21 & 0.0488 \\
\hline
\end{tabular}

Model terms: $\mathrm{A}=$ wax, $\mathrm{B}=$ surfactant, $\mathrm{C}=$ defoamer

Table 13 ANOVA statistics for rub resistance

\begin{tabular}{ll}
\hline Standard deviation & 0.34 \\
Mean & 4.97 \\
Coefficient of variance \% & 6.83 \\
$R$-squared & 0.9298 \\
Adequate precision & 6.380 \\
\hline
\end{tabular}

The linear model for rub resistance derived from data fitting is given in Eq. 2. From the coefficients, it can be seen that wax has the largest effect on rub resistance, as indicated by its larger coefficient value of 0.2665 compared with surfactant and defoamer, which have coefficient values of 0.1796 and 0.1446 , respectively. To optimize rub resistance, the mass fraction of wax relative to surfactant and defoamer can be increased in the ink formulation to obtain a printed ink with high rub resistance

$$
y=0.266 x_{A}+0.180 x_{B}+0.145 x_{C},
$$

where $A=$ wax, $B=$ surfactant, $C=$ defoamer.

The contour plot of the model equation determined for the response is shown in Fig. 8, with the color scheme showing the trend of the response is also indicated, while the $3 \mathrm{D}$ views of the response surface are shown in Figs. 9, 10. Based from the model graphs, it can be seen that high rub resistance favors the formulation close to that with pure wax.

The lowest rub resistance values correspond to the formulation purely containing the defoamer, which is Formulation $\mathrm{H}$, which is expected since the mineral oil defoamer leaves behind ink particles (from small defoamer droplets) after drying, which can be rubbed easily because they migrate to the surface [18]. On the other hand, the region near the high mass fractions of wax achieves high rub resistance because hard wax particles protrude in the ink surface and act as physical spacer between a rubbing medium and the surface [19], thereby reducing the amount of ink removed during rubbing.

\section{Gloss}

The results from model fitting and analysis of variance for adhesion are presented in Tables 14, 15. Similar to adhesion, the model used is a special cubic model are A, B, C, $\mathrm{AB}, \mathrm{AC}, \mathrm{BC}$, and $\mathrm{ABC}$ and the significant terms for the model were determined. In this study, a $p$-value less than 0.0500 is the criterion use to define significance of the terms; thus, the terms A, B, C, and BC are significant. However, the model has an $R$-squared value of 0.9961 , which implies a very good data fit of the special cubic equation even without excluding the three interactions parameters. 


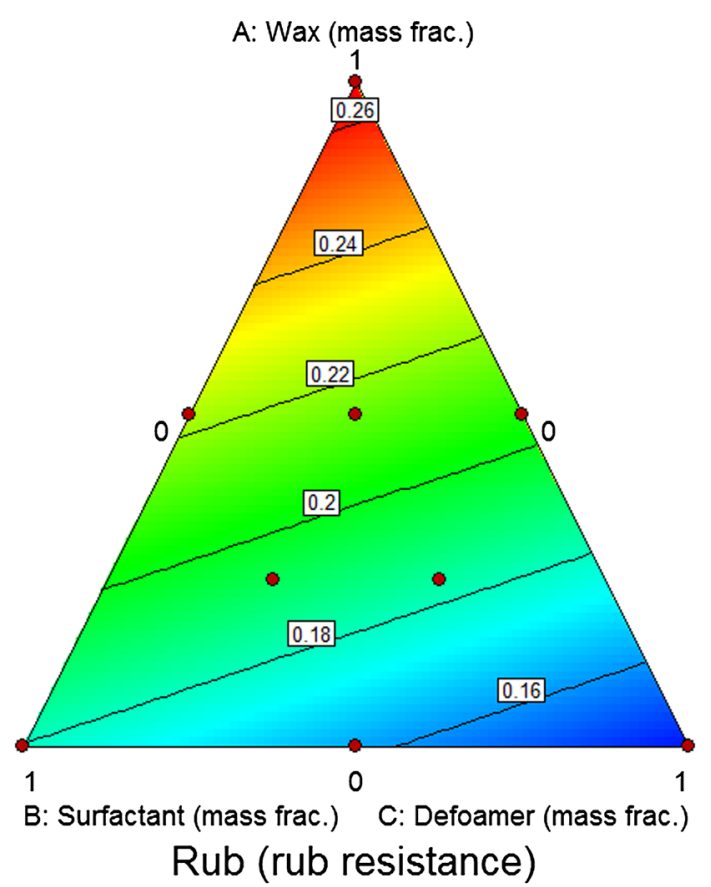

Fig. 8 Rub resistance contour plot

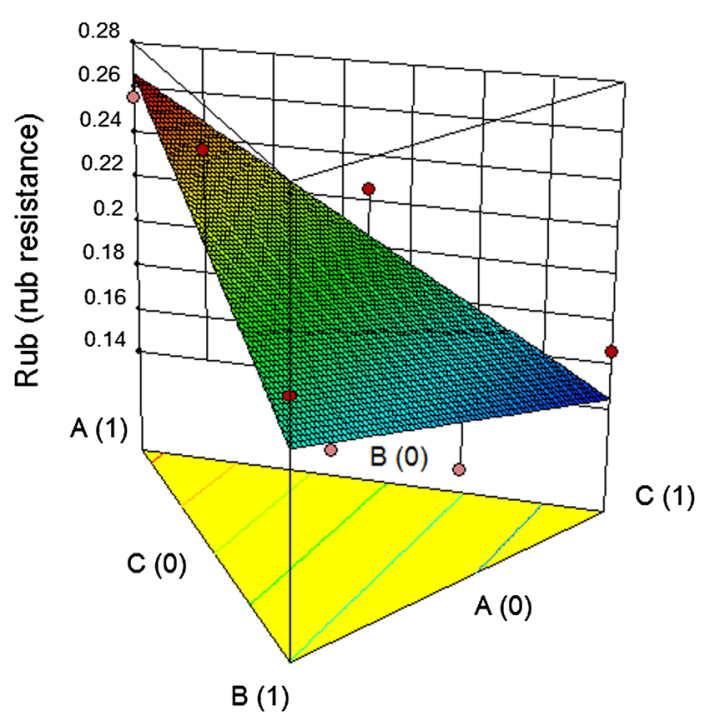

Fig. 9 Rub resistance 3D response surface

The special cubic model for adhesion with the coefficients from data fitting is given in Eq. 1. From the model coefficients, it can be seen that among the main terms, the mass fraction of the surfactant has the largest effect on gloss compared to both those of the wax and defoamer; thus, to optimize the gloss, the mass fraction of surfactant relative to wax and defoamer can be increased in the ink formulation. For the interaction parameters, the wax and defoamer combination is found to be the only one to have a synergistic effect on gloss 


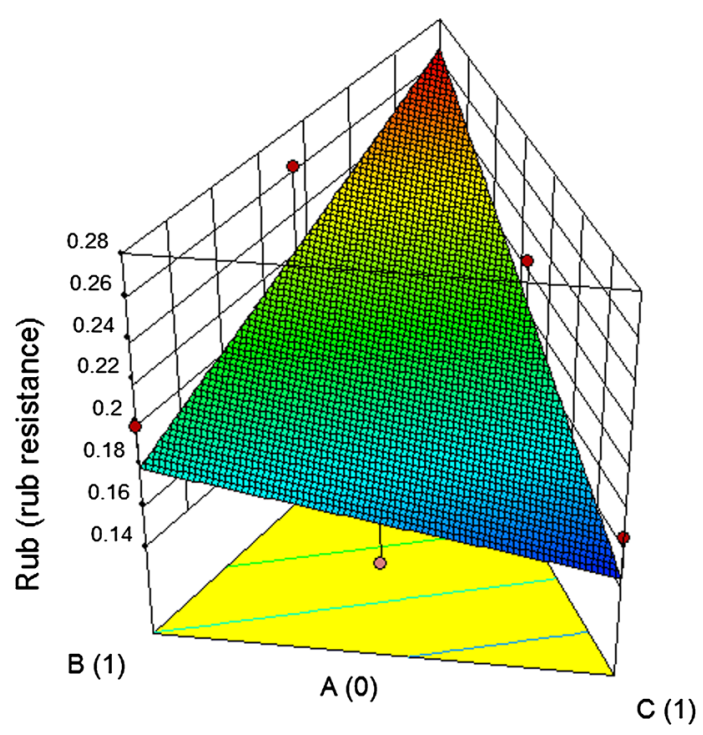

Fig. 10 Rub resistance 3D response surface (rotated)

Table 14 ANOVA for gloss mixture model

\begin{tabular}{lcllll}
\hline Source & Sum of squares & Degrees of freedom & Mean square & F value & $\begin{array}{l}\boldsymbol{p} \text { value } \\
\text { Prob }>\boldsymbol{F}\end{array}$ \\
\hline Model & 367.04 & 6 & 61.2 & 85.0 & 0.0117 \\
Linear mixture & 235.61 & 2 & 118 & 164 & 0.00610 \\
AB & 9.61 & 1 & 9.61 & 13.4 & 0.0674 \\
AC & 0.11 & 1 & 0.110 & 0.150 & 0.735 \\
BC & 69.44 & 1 & 69.4 & 96.5 & 0.0102 \\
ABC & 3.96 & 1 & 3.96 & 5.50 & 0.144 \\
\hline
\end{tabular}

Model terms: $\mathrm{A}=$ wax, $\mathrm{B}=$ surfactant $\mathrm{C}=$ defoamer

Table 15 ANOVA statistics for adhesion

\begin{tabular}{lr}
\hline Standard deviation & 0.85 \\
Mean & 21.99 \\
Coefficient of variance \% & 3.86 \\
$R$-squared & 0.9961 \\
Adequate precision & 29.683 \\
\hline
\end{tabular}

$$
\begin{aligned}
y= & 19.52 x_{A}+38.91 x_{B}+19.53 x_{C} \\
& -15.06 x_{A} x_{B}+1.602 x_{A} x_{C} \\
& -40.53 x_{B} x_{C}-5.957 x_{A} x_{B} x_{C},
\end{aligned}
$$

where $A=$ wax, $B=$ surfactant, $C=$ defoamer.

The contour plot of the model equation determined for the response is shown in Fig. 11 and the 3D views of the response surface are shown in Figs. 12, 13. Based on the graphs, the highest gloss would be given by the formulation containing solely of the surfactant; gloss is affected by the presence of the surfactant since it is composed of an ether mixed with ethylene oxide and propylene oxide groups (commonly found in non-ionic 


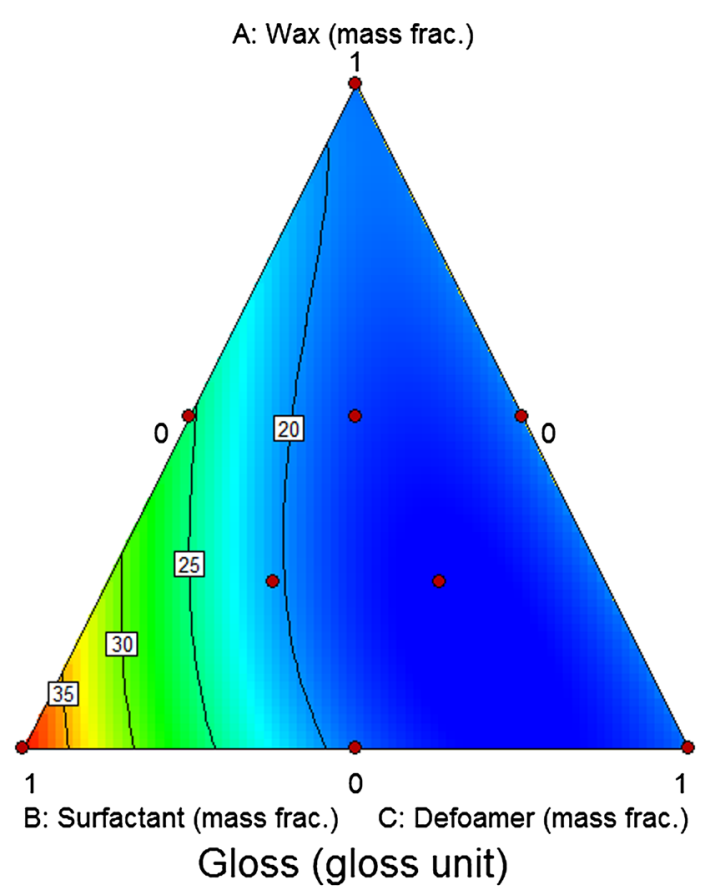

Fig. 11 Gloss Contour Plot

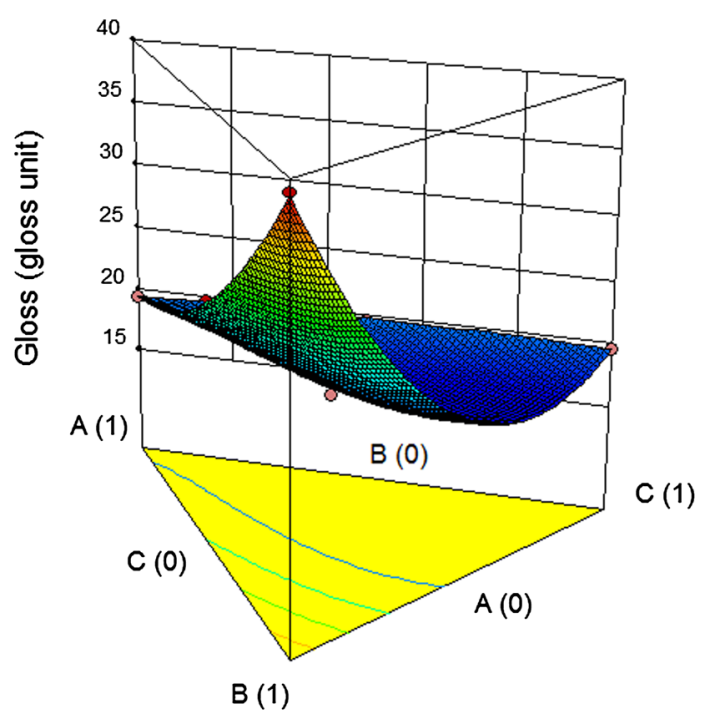

Fig. 12 Gloss 3D response surface

surfactants) that tend to form a clear smooth layer of liquid at the surface when present in significant excess.

On the other hand, the lowest gloss values correspond to Formulation $\mathrm{H}$ and Formulation I, which contain purely of the wax and of the defoamer, respectively. The excess hardened polyethylene wax particles protrude and form a rough layer on the ink surface, while the excess defoamer result in the production of insoluble opaque, off-white liquid particles that migrate to the surface and form rough micro patches during drying. 


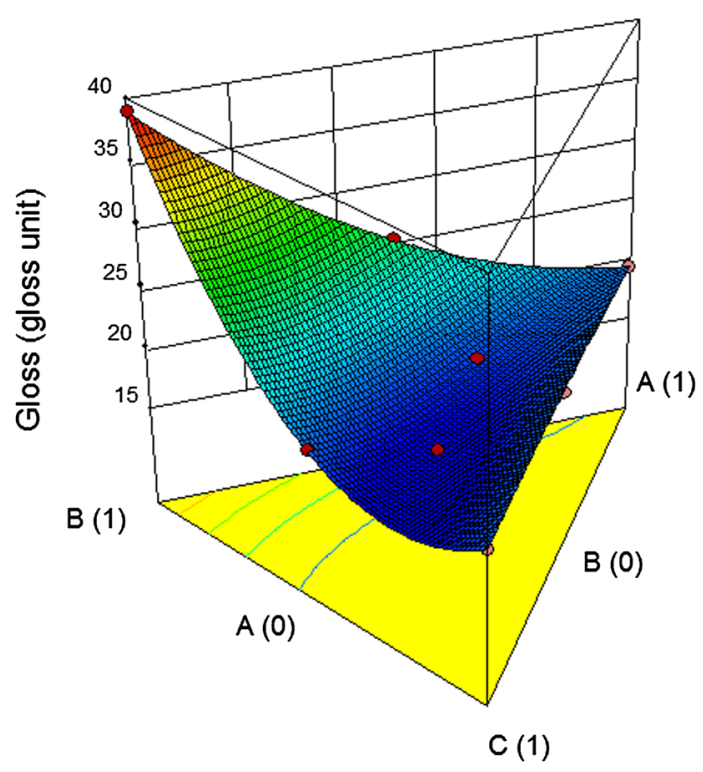

Fig. 13 Gloss 3D response surface (rotated)

\section{Optimization}

Numerical optimization is done to determine solutions by using a multi-response optimization method that maximize an objective function called the desirability function. The response is then transformed into an individual desirability function, $d$, that ranges from zero to one (with one being the most favorable). To maximize a response, $d$ is defined as:

$$
d=\frac{y-L}{U-L}
$$

where $y$ is the response, $L$ is the lower value limit and $U$ is the upper value limit of the response. The individual desirability functions of the three responses are combined into a single overall desirability, $D$, which is the geometric mean:

$$
\boldsymbol{D}=\left(d_{1}^{w_{1}} \cdot d_{1}^{w_{1}} \cdot d_{1}^{w_{1}}\right)^{\frac{1}{\sum w}}
$$

where $d_{1}, d_{2}$, and $d_{3}$ are the individual desirability functions of the three responses, and $w_{1}, w_{2}$, and $w_{3}$ are the weights assigned for each response. The objective is to maximize the value of $D$, which will be equal to 1 when all the responses are on target limits $(d=1)$ and equal to zero if any of the responses is outside the limits $(d=0)$. Otherwise, the value of the overall desirability will be between zero and one [20].

The objective of the optimization study is to maximize all the responses: the lower limit is adjusted to the lowest acceptable response value, while the upper limit is represented by the highest response value from the actual data. Simultaneous optimization is done for the three components, and each response must have a low and high value assigned to each goal. In this study, the mass fractions of the three additives and the desirability for each solution are shown in Table 16: 
Table 16 Numerical optimization criteria

\begin{tabular}{llll}
\hline & Goal & Lower limit & Upper limit \\
\hline Wax & In range & 0 & 1 \\
Surfactant & In range & 0 & 1 \\
Defoamer & In range & 0 & 1 \\
Adhesion & Maximize & 5 & 6 \\
Rub & Maximize & 0.16 & 0.24 \\
Gloss & Maximize & 22 & 30 \\
\hline
\end{tabular}

The individual and overall desirabilities of the two solutions found are presented in Fig. 14. It is important to note that the goal of the optimization is to find a good set of conditions that will meet all the goals and not to get a desirability value of 1.0. Determining an optimum region is done regardless of the value of the desirability.

The contour plots and 3D surfaces of the desirability are shown in Figs. 15, 16. Among the individual desirability values, rub resistance has the highest achieved value, followed by adhesion and gloss. Thus, it can be concluded that the determined optimum formulation lies near the region of high rub resistance. It can also be seen that the area satisfying the optimization criteria set lies on the region of wax and surfactant (no defoamer). Therefore, based from the ink formulations, the formulation that is close to the optimum composition is Formulation D, which contains equal mass fractions of wax and surfactant, 0.500 and 0.500 , respectively (minimum defoamer).

\section{Conclusion and recommendation}

The print property test methods developed and proposed in this study are significantly more quantitative compared to the standard test methods used in the industry. For adhesion, the quantitative test method provides a more accurate evaluation of adhesion by getting the actual amount of ink adhered on the substrate. It is more accurate compared

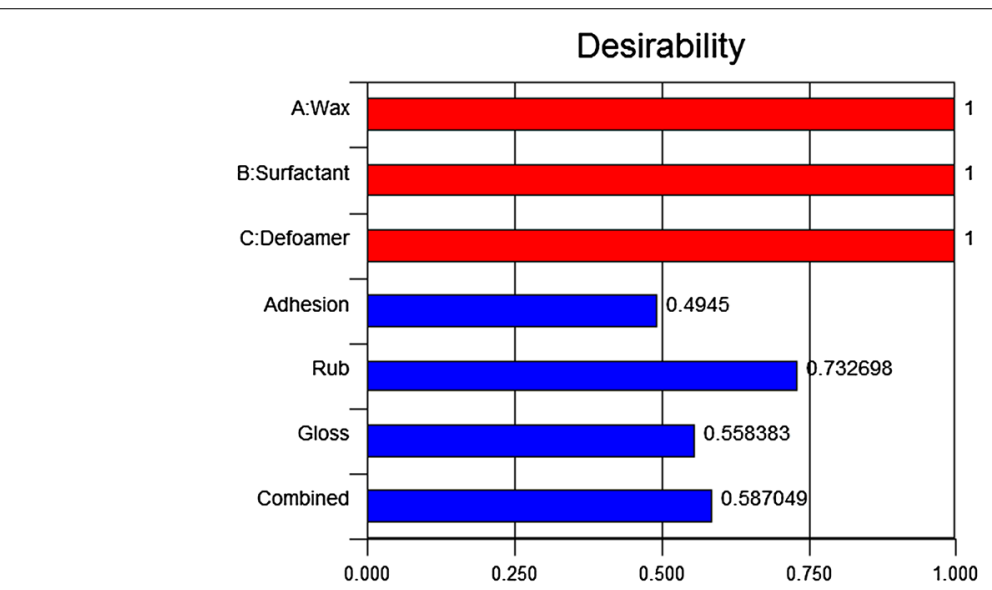

Fig. 14 Individual and overall desirabilities 


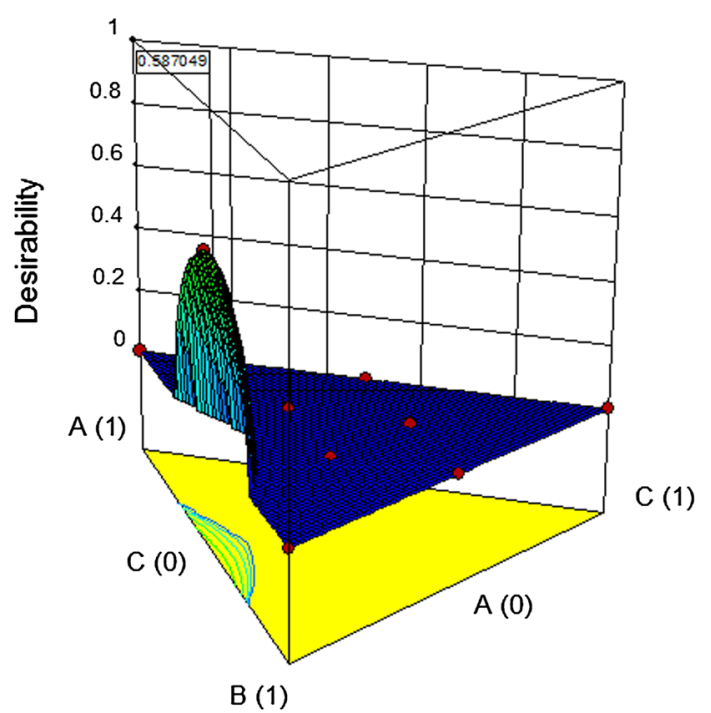

Fig. 15 Desirability 3D response surface and contour plot

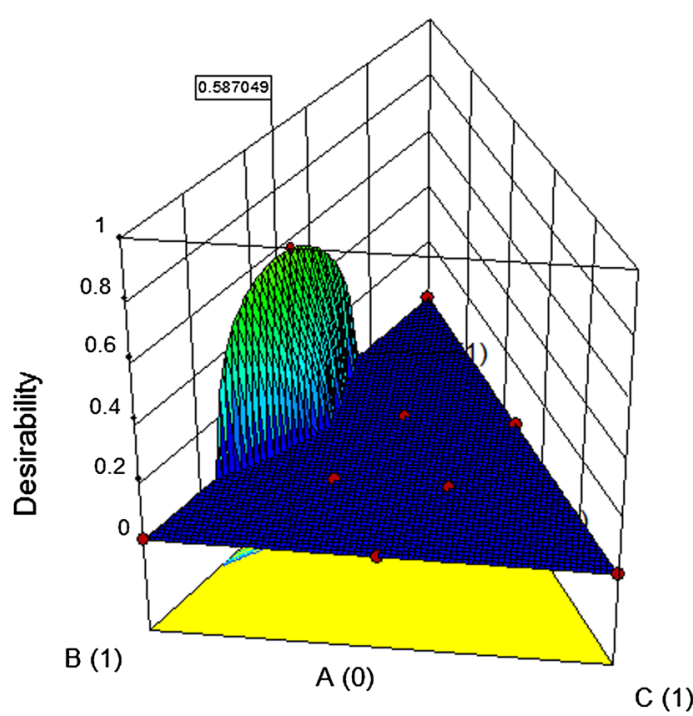

Fig. 16 Desirability 3D response surface and contour plot (rotated)

to the mostly qualitative ASTM standard test method. For rub resistance, the quantitative method provides a significantly accurate evaluation of rub resistance by getting the actual degree of rubbing of the ink adhered on the substrate based on the total amount of color change of the rubbed ink to represent the actual degree of rubbing. Again, this is also more accurate compared to the ASTM standard test method that involves a totally qualitative assessment of rub resistance. Based from the experimental results, the proposed methods can be feasibly adopted for use in the industry.

From all of the water-based ink formulations used in this study, the formulation that best corresponds to the optimum mass fractions of additives determined is to be 0.50 wax, 0.50 surfactant, and no defoamer. It can be concluded that for the optimization 
criteria set for this study, the optimum formulation would contain only wax and surfactant and no defoamer.

The scope of the study can be extended to printing to treated polyethylene films, or to other polymer films commonly used in the ink and printing industry including polypropylene films, since both plastics are popularly used in many printing applications including packaging and publications. Additionally, study for other print properties like scratch resistance, crinkle resistance, and wet rub resistance can be done. Resistance properties of the dried ink are important in many printing applications. It would be an essential contribution if these properties are also studied. Also, it is recommended to use other mixture designs of experiment like simplex lattice or augmented simplex lattice for modeling and optimization of the print properties. Lastly, cost analysis can be included in the study for the water-based ink formulations: it is recommended to also develop a cost equation that would describe the cost of the ink as a function of the ink components under study, which is in this case the three additives by including the cost as another response in the optimization.

\section{Authors' contributions}

JCCR conducted the experiments as part of his master's thesis. TPT helped formulate the image-based analytical procedure in relation to the adhesion, rub resistance and gloss of the ink, and guided JCCR with setting up the theoretical framework behind such ink property relations. Both authors read and approved the final manuscript.

\section{Acknowledgements}

The authors would like to acknowledge the Engineering Research and Development for Technology (ERDT) program of the Department of Science of Technology (DOST) for funding this research.

\section{Competing interests}

The authors declare that they have no competing interests.

Availability of data and materials

May be made available upon request.

Consent for publication

Not applicable.

Ethics approval and consent to participate

Not applicable.

\section{Funding}

The project was funded by the Department of Science and Technology (DOST) under the Engineering Research and Development for Technology (ERDT) program.

\section{Publisher's Note}

Springer Nature remains neutral with regard to jurisdictional claims in published maps and institutional affiliations.

Received: 22 November 2017 Accepted: 29 December 2017

Published online: 13 January 2018

\section{References}

1. Izdebska J, Thomas S. Printing on polymers: fundamentals and applications. Amsterdam: Elsevier; 2016

2. Zolek-Tryznowska Z, Izdebska J, Tryznowski M. Branched polyglycerols as performance additives for water-based flexographic printing inks. Prog Org Coat. 2015;78:334-9.

3. Zolek-Tryznowska Z. Additives for Ink Manufacture. In: Printing on polymers: fundamentals and applications. 2016. pp. 57-66.

4. Glockner P, Jung T, Struck S, Studer K. Radiation curing: coatings and printing inks-technical basics, applications and trouble shooting. Hannover: Vincentz Network, GmbH \& Co. KG; 2008. p. 89-92.

5. Rentzhog M, Fogden A. Print quality and resistance for water-based flexography on polymer-coated boards: dependence on ink formulation and substrate pretreatment. Prog Org Coat. 2006;57:183-94.

6. Pekarovicova A, Husovska V. Printing ink formulations. In: Izdebska J, Thomas S, editors. Printing on polymers: fundamentals and applications. Oxford: Elsevier, Inc.; 2016. pp. 41-55. 
7. Leach R. The printing ink manual. 4th ed. Berkshire: Society of British Printing Ink Manufacturers Ltd. Van Nostrand Reinhold (International) Co. Ltd.; 1988.

8. Zolek-Tryznowska Z, Izdebska J. Flexographic printing ink modified with hyperbranched polymers: BoltornTM P500 and BoltornTM P1000. Dyes Pigments. 2013;96:602-8.

9. Awaja F, Gilbert M, Kelly G, Fox B, Pigram P. Adhesion on polymers. Prog Polym Sci. 2009;34:948-68.

10. Cornell J. Experiments with mixtures: designs, models, and the analysis of mixture data. 3rd ed. Hoboken: Wiley; 2002.

11. Myers R, Montgomery D. Response Surface methodology: process and product optimization using designed experiments. 4th ed. Hoboken: Wiley; 2016. p. 693-720.

12. Bazrafshan Z, Ataeefard M, Nourmohammadian F. Modeling the effect of pigments and processing parameters in polymeric composite for printing ink application using the response surface methodology. Prog Org Coat. 2015;82:68-73.

13. Myers R, Montgomery D, Anderson-Cook C. Response surface methodology: process and product optimization using designed experiments. 3rd ed. Hoboken: Wiley; 2016. p. 261-6.

14. Romsted L. Surfactant science and technology: retrospects and prospects. Boca Raton: CRC Press; 2014

15. Brutin D. Droplet wetting and evaporation: from pure to complex fluids. Amsterdam: Elsevier; 2015. p. 3-13.

16. Acton Q. Polyvinyls_-advances in research and application. 2013th ed. Berlin: Springer Science \& Business Media; 2013. p. 679-80.

17. Abdolahi F, Mohammad A, Vatani M, Vatani M. The Mechanism of Action of Antifoams. J Appl Sci. 2005;5(6):1122-1129.

18. Tracton A. Coatings technology handbook. 2nd ed. New York: Marcel Dekker, Inc.; 2001.

19. Tracton A. Coating materials and surface coatings. Boca Raton: CRC Press; 2006.

20. Costa N, Lourenço J, Pereira Z. Desirability function approach: a review and performance evaluation in adverse conditions. Chemom Intell Lab Syst. 2011;107(2):234-44.

\section{Submit your manuscript to a SpringerOpen ${ }^{\odot}$ journal and benefit from:}

- Convenient online submission

- Rigorous peer review

- Open access: articles freely available online

- High visibility within the field

- Retaining the copyright to your article

Submit your next manuscript at $\gg$ springeropen.com 